\title{
Editorial
}

\section{Dr Leon Sebastian Illis, MD, BSc, FRCP}

Spinal Cord (2006) 44, 337-338. doi:10.1038/sj.sc.3101925

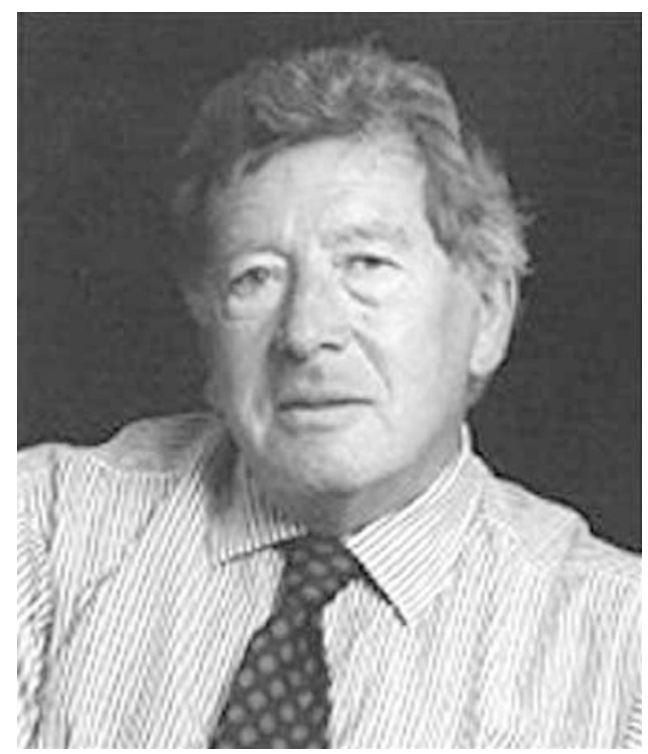

In 1997, Dr Illis, a physician, neurologist, researcher, neuroscientist, and teacher became the Editor of Spinal Cord. Within 9 years of his remarkable leadership, he succeeded in increasing the impact factor of the Journal, and decreasing the wait time for a decision of submitted manuscripts. Dr Illis also introduced, to the regular Journal content, review articles and other publications from experimental work. As a result of his tenure at Spinal Cord, the journal became a high quality, 'multidisciplinary forum for basic science, clinical and applied studies'. To act, as 'the international voice of the spinal cord' is the stated purpose of the Journal, and by expressing this in his work as an editor, he leaves the journal as an influential and widely received publication.

The ability that Dr Illis has of attracting interest from authors as well as readers for Spinal Cord is the direct result of his career as a physician, neurologist, as well as his pioneering experimental work in regeneration and reorganization in the central nervous system. During his medical studies at the University College of London, London, UK, Dr Illis was the Anatomy Scholar under the tutelage of the famous neurobiologist Professor JZ Young, (of the Department of Anatomy of University College London) who is the author of well-known and highly recognized basic work on brain functions, summarized in his book titled 'A Model of the Brain', published by Oxford University Press 1964.
In 1963, Dr Illis gave what was perhaps the first proper explanation for Spinal Shock (Experimental Neurology), and, as an example of his wide-ranging interests, the explanation of the origin of the werewolf myth (Proceedings of the Royal Society of Medicine, 1964)!

Dr Illis's MD thesis at the University College of London in 1964 is titled 'Boutons Termineaux and Application to Neurology'. This he followed with two publications in the high-ranking neurological Journal, Brain, on normal appearance and reaction to motoneuron surface of the spinal cord synapses in the cat. Only 3 years later, in 1969, he published a research article in the Journal Nature, on 'Enlargement of spinal cord synapses after repetitive stimulation.' This is seminal experimental work 'on demonstration that repetitive stimulation would produce a structural change in the nervous system.' Dr Illis suggested that the clinical features due to a damaged nervous system should be capable of improvement with repetitive stimulation. Thus 37 years ago, he demonstrated biological mechanisms for neuromodulation by repetitive stimulation, which we are today not only more familiar with but very much involved in studying how to optimize this effect of repetitive stretch, repetitive steps, repetitive electrical stimulus, repetitive pharmacological spinal and brain network activation and other modalities in order to recover impaired movement.

Dr Illis' research work became the scientific background for his clinical work as a Consultant Neurologist at the Wessex Neurological Centre, Southampton University. During this part of his career, 40 years ago, neuroscientist and neurologist he established the understanding that 'following partial denervation the intact CNS would react in such a way that unused or little used pathways would become more effective.' This concept and application of it in clinical practice is well documented in his 74 scientific papers, 15 chapters and four edited books.

Before his eventual role as editor for Spinal Cord, Dr Illis contributed chapters to three notable volumes of books on Spinal cord Dysfunction: Volume 1 - Clinical \& Physiological Assessment, Oxford University Press, 1988; Volume II - Intervention and Treatment, Oxford Press, 1991; Volume III - Functional Stimulation, Oxford University Press, 1992. In the Foreword of the 1st volume, Patrick D Wall summarized the capital work of Sir Ludwig Guttman, in the concise sentence 
'who (Sir Ludwig Guttman) through good nursing practice, by use of sterile techniques and antibiotics, by movement, and, above all, by raising the morale both of staff and of patients' prevented deterioration of spinal cord patients' health condition. In the same Foreword, PD Wall asked 'what to do next?' Dr Illis addressed the question in his subsequent three volumes.

Through all 40 and more years of Dr Illis' work, academic, clinical, research, it is clear that he carries a keen awareness and often emphasizes the interdependence between clinical and experimental work. His life's work is a carefully executed emphasis on the need of professionals who talk to spinal cord injury patients to interact with patients and physicians and actively assist with the full responsibility of a consultant to the care program. Furthermore, he demonstrates how necessary it is for the physician to also be comfortable with basic science and be capable of facilitating the transfer of scientific accomplishments to the care program.

Dr Illis is a frequent, invited speaker, visiting professor, consultant, member of editorial boards in addition to Spinal Cord, Past President of the International Neuromodulation Society, Founder Member of the Society for Research and Rehabilitation of UK, Disability Advisory Board of UK Department of
Health, Chief Medical Officer's Expert Group on Chronic Fatigue Syndrome, Elected Trustee of the International Spinal Research Trust, Founder Member of Society of Expert Witnesses, Member of the Expert Witness Institute and many more.

I wish and hope that Dr Illis, after being relieved from the time demanding and consuming job as Editor, will join in advancing education for physicians and scientists involved in the treatment of acute and functional repair of chronic dysfunction of the spinal cord injury. However, 'much basic sciences as directed at imagined clinical problems, which do not relate to actual problems. There is crucial work to be done short of the complete restoration of connection.'

Experimental scientists are setting the stage for functional repair of spinal cord injuries and who is more qualified than Dr Illis to initiate what he has been doing so successfully all along; recognizing interdependence between clinical practice and research.

MR Dimitrijevic MD, $\mathrm{PhD}$ and VL Smith Professor Baylor College of Medicine, Houston, Texas, USA. E-mail:naisus@cs.com 